\title{
Multiple stents are not superior to single stent insertion for pain relief in patients with chronic pancreatitis: a retrospective comparative study
}

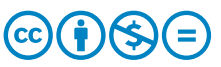

\author{
Authors \\ Lavrentios Papalavrentios, Carmen Musala, Paraskevas Gkolfakis, Jacques Devière, Myriam Delhaye, Marianna \\ Arvanitakis
}

Institution

Erasme University Hospital, Université Libre de Bruxelles, Division of Gastroenterology, Hepatopancreatology and Digestive Oncology, Brussels, Belgium

submitted 8.5.2019

accepted after revision 22.7.2019

Bibliography

DOI https://doi.org/10.1055/a-1006-2658 |

Endoscopy International Open 2019; 07: E1595-E1604

(c) Georg Thieme Verlag KG Stuttgart · New York eISSN 2196-9736

Corresponding author

Marianna Arvanitakis, MD PhD, Department of

Gastroenterology, Hepatopancreatology and Digestive

Oncology, ULB Erasme Hospital, Route de Lennik 808,

1070 Brussels, Belgium

Fax: +3225554697

Marianna.Arvanitaki@erasme.ulb.ac.be

\section{ABSTRACT}

Background and study aims Patients with painful chronic pancreatitis (CP) and distal main pancreatic duct (MPD) stricture are considered candidates for treatment using a single plastic stent insertion. Multiple side-by-side stents have been proposed as an alternative treatment but comparative studies are lacking. The aim of this retrospective study is to assess differences in characteristics and treatment outcomes in patients with CP and MPD strictures treated with a different number of stents during the stenting period.

Patients and methods Patients with painful CP and distal MPD obstruction requiring endoscopic treatment (01.2004-12.2012) were considered. The study population was divided in three groups: Patients treated with (A) exclusively one stent; (B) one or two stents; and (C) exclusively two stents during the stenting period. Patient characteristics and treatment outcomes were retrospectively assessed.

Results Among 284 patients, 85 were selected according to inclusion criteria (Group A: 18, Group B: 35, Group C: 32). Median follow-up duration was 84 months. The median number of endoscopic procedures needed was higher for group B [3 (A) vs. 3 (C) vs. 4 (B), $P=0.001$ ]. Regarding outcome, successful endoscopic treatment was lower in Group $C$ ( $50 \%$ vs. $88.2 \%$ and $74.2 \%$ for groups $A$ and $B$, respectively; $P=0.02)$. This difference was attributed to better clinical outcome in Group A compared to Group C patients [OR (95\%Cl): 7.50 (1.46-38.70); $P=0.04]$. Moreover, group $C$ patients experienced higher levels of pain at the end of follow-up period [median Izbicki Score 0 (group A) vs. 0 (group B) vs. 6 (group C), $P=0.03$ ].

Conclusions In patients with painful CP and distal MPD obstruction, treatment with a single stent is associated with better clinical outcome compared to treatment with exclusively two stents during the stenting period.

\section{Introduction}

Chronic pancreatitis $(C P)$ is defined as a progressive fibro-inflammatory process with specific morphological changes in the pancreatic parenchyma and the pancreatic ducts leading to pancreatic exocrine and endocrine insufficiency [1]. Persistent or relapsing pain is a common symptom and pain relief is the major goal of endoscopic treatment [2]. Among causes of pancreatic pain, dominant strictures of the main pancreatic duct (MPD), usually located at the head of the pancreas, are common indications for endoscopic treatment. It is well substantiated that pancreatic stent placement offers a satisfactory long-term clinical response. Thus, the European Society of Gastrointestinal Endoscopy (ESGE) has recommended treating MPD stricture by inserting a single $10 \mathrm{Fr}$ plastic stent with stent exchange planned within 1 year [3].

Placement of multiple parallel pancreatic stents for treatment of dominant pancreatic head MPD strictures has been 
proposed as an alternative treatment option with promising results [4]. However, the efficacy of this treatment modality has not been validated in randomized controlled trials (RCTs) and its role remains unclear. Nevertheless, simultaneous placement of multiple pancreatic stents could be applied more extensively, particularly in patients with MPD strictures persisting after 12 months of single plastic stenting [5].

The aim of this study was to evaluate differences in treatment characteristics and outcomes between patients with $\mathrm{CP}$ and MPD strictures treated by single or multiple pancreatic stents.

\section{Patients and methods}

We retrospectively reviewed patients older than 18 years old who underwent endoscopic treatment in our clinic between January 2004 and December 2012 due to painful CP defined as continuous or recurrent pain with at least three painful episodes per year and a MPD stricture in the head of pancreas. Diagnosis of CP was based on morphological findings consisting of a distal stricture with upstream dilation $(>3.5 \mathrm{~mm}$ ) demonstrated by magnetic resonance cholangiopancreatography (MRCP) or endoscopic retrograde cholangiopancreatography (ERCP).

Patients were excluded from the study according to the following criteria; previous pancreatic surgery, presence of a pancreatic pseudocyst $\geq 2 \mathrm{~cm}$ or a biliary stricture, total duration of follow-up (FU) < 24 months since stent insertion, and pancreatic cancer diagnosed during FU.

The study population was divided into three groups: (A) patients treated with exclusively one stent; (B) patients treated with one or two stents; and (C) patients treated exclusively with two stents during the stenting period, respectively.

Data collected included pain severity assessment according to Izbicki score (IS) [6], smoking and alcohol abuse, and presence of exocrine or endocrine insufficiency depending on the need of pancreatic enzymes supplementation and antidiabetic drugs and/or subcutaneous insulin administration. The study was approved by the ethics committee of our institution.

\section{Endoscopic procedures}

All procedures were performed under general anesthesia with endotracheal intubation. If obstructive MPD stones had been previously identified on imaging, extracorporeal shockwave lithotripsy (ESWL) (Siemens Lithoskop) preceded ERCP to obtain stone fragmentation. The first step of the endoscopic treatment included pancreatic sphincterotomy of the major or minor papilla according to the ductal anatomy after insertion of a 0.020 - or 0.035 -inch hydrophilic guidewire in the MPD (Radiofocus, Terumo Europe N.V., Leuven, Belgium; Jagwire Super Stiff, Boston Scientific, Galway, Ireland). In case of pancreatic stones, endoscopic stone extraction was performed using a Dormia basket after stricture dilation using either a graduated (6-10 Fr) Teflon bougie (Wilson-Cook Medical Inc., Limerick, Ireland) or, more often, a hydrostatic balloon catheter of 4- to 6-mm diameter (Maxforce or Hurricane, Boston Scientific, Galway, Ireland). In case of tight strictures, the Soehendra stent re- triever (Wilson-Cook Medical Inc, Limerick, Ireland) was used. In cases of residual fragments after ESWL or very tight stricture a naso-pancreatic catheter for saline lavage or drainage was left in place for 24 to 48 hours after dilation and before pancreatic stenting to facilitate elimination of stone fragments. Insertion of a single or multiple stents insertion was individualized according to the endoscopist's judgment based on clinical evaluation and morphological MPD features to obtain optimal ductal drainage. The plastic stents used were 8.5 to $10 \mathrm{Fr}$ straight polyethylene Amsterdam-type design with both an internal and external flap. Their length was chosen according to stricture's length tailored from the pancreatic sphincter's orifice. The stents were deployed over a guiding catheter, which had been inserted beyond the stricture over the guide wire. Multiple stenting consisted of deployment of two side-by-side plastic stents, after dilation with a hydrostatic balloon parallel to the first stent to facilitate insertion of the second one. The Fusion introducer (Cook Medical Inc, Limerick, Ireland fusion) was used to allow intraductal exchange in case of multiple stents insertion ( $>$ Video $\mathbf{1})$.

\section{Definitions and classifications}

Successful endoscopic treatment was defined as IS $\leq 10$ at the end of the stenting period. Partial response to endoscopic treatment was defined as IS > 10 after an initial decrease of $>50 \%$ and absence of response as IS >10 after an initial decrease of $<50 \%$ or need for surgery. For outcome analysis, partial and absent response were considered failures of endoscopic treatment. Patients' ongoing stenting at the time of the study was not included in the outcome analysis.

Duration of FU was defined as the time from initial intervention to the last visit/call appointment, surgery or death. "Ondemand” stent exchange strategy for pancreatic pain recurrence was performed.

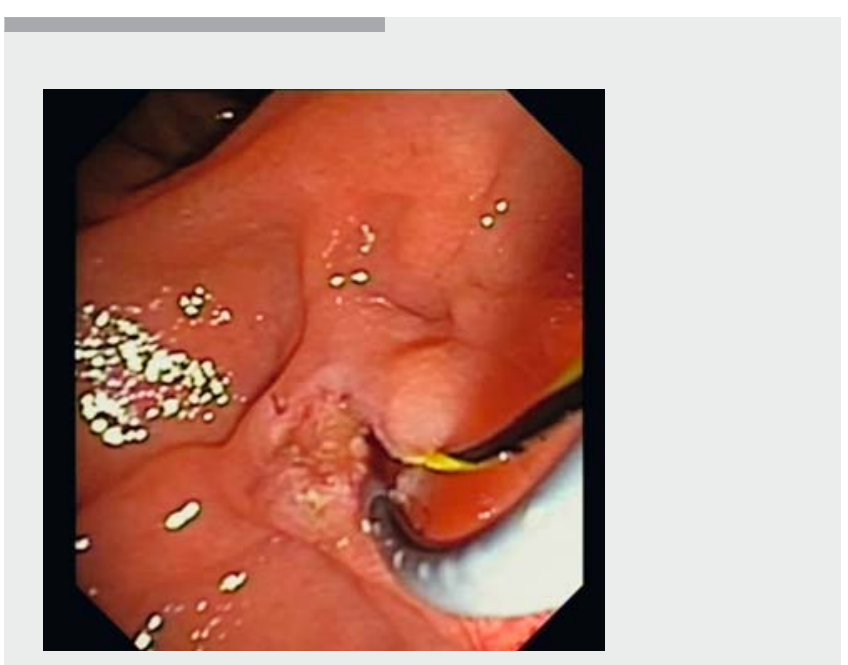

$\checkmark$ Video 1 Patient with chronic pancreatitis and distal MPD stricture treated by two plastic stents. The Fusion introducer is used to facilitate stent placement. Balloon dilation $(6 \mathrm{~mm})$ is performed before insertion of the second stent. 
Definitive stent removal was defined as stent removal with no intent to replace it. It was performed after stricture resolution and significant pain improvement according to IS (IS < 10/ 100).

Stricture resolution was defined as at least one of the following: a) sufficient flow of contrast medium alongside of a $6 \mathrm{Fr}$ naso-pancreatic catheter during ERCP or b) absence of pain during perfusion of the naso-pancreatic catheter with normal saline (1/t/24h) [7].

The stenting period was defined as the duration of stenting from the initial insertion till definitive removal. In case of distal (in the duodenal lumen) stent migration during FU without immediate stent replacement, the stenting period was defined as the interval between stent insertion and the last FU visit with the stent in place. Finally, re-stenting was defined as any new period of stenting after definitive stent removal because of pain recurrence and MPD dilation.

The primary objective of the study was to evaluate the three different groups in terms of a) different treatment characteristics and b) outcome of endoscopic treatment. Secondary objectives included definitive stent removal, duration of stenting, stent migration rate, number of procedures needed, need for re-stenting after definitive stent removal, and presence of endo-and exocrine insufficiency at the end of FU. We also aimed to identify potential predicting factors of successful endoscopic treatment outcome.

\section{Statistical analysis}

Statistical analysis was performed using the Statistical Package for Social Sciences (IBM SPSS Statistics, Version 22.0. Armonk, New York, United States: IBM Corp). Continuous data are reported as median and interquartile range (IQR). Differences between groups were evaluated using Mann-Whitney or KruskallWallis test in case of continuous data and chi-square or Fischer's exact test in case of categorical data. In case of statistically significant differences, we performed multiple comparisons to evaluate intergroup differences. Moreover, we calculated the proportional difference in outcome between the three groups and specified the estimation uncertainty using $95 \% \mathrm{Cl}$. Regarding our primary objective, we performed univariate and multivariable analysis using binomial logistic regression to identify factors predicting clinical success. In the multivariable model we included factors that were significantly associated to the outcome in the univariate analysis $(P<0.1)$. In the univariate analysis we included factors that a) differed significantly between the three groups in baseline and b) have been shown to be associated to clinical outcome in the current literature. The Homers-Lemeshow test was used to check the goodness-of-fit of the multivariable regression model. Interaction was tested between each significant factor. Odds ratios and their $95 \% \mathrm{Cl}$ were derived from each variable coefficient in the final model. The significance of each coefficient was tested by the Wald test. Statistical significance was considered for $P$ values $\leq 0.05$.

\section{Results}

\section{Patient characteristics}

During the study period, a total of 284 CP patients undergoing pancreatic stenting for pain management were identified. After exclusion of patients according to study's exclusion criteria 85 patients were further considered eligible for inclusion. - Fig. 1 depicts study's flowchart. Sixty-one (73\%) of them were men. The median age of the study population was 51 years $(42-59)$. CP etiology was alcoholic in the majority of patients $(n=57,67 \%)$. Pancreas divisum was evident in seven patients ( $8 \%$ ). Median disease duration before initial endoscopic treatment was 25 months $(8-82)$. Groups A, B and C consisted of 18,35 and 32 patients, respectively. Four patients (1 in group A, 2 in group B and 1 in group C) died during the FU period and three patients ( 2 in group $B$ and 1 in group $C$ ) were still under endoscopic treatment at the time of the study. All deaths were irrelevant to the endoscopic procedures. Patients were followed up for a median period of 84 months (55-108). The demographic and clinical characteristics of the 85 patients at the beginning of endoscopic treatment are presented per group in $>$ Table 1 . There were no significant differences between the three groups except a lower rate of patients undergoing ESWL at the beginning of endoscopic treatment in group B (46\% (B) vs. $78 \%$ (A) vs. $75 \%(C), P=0.02)$.

\section{Per group analysis}

\section{Group A - Exclusive use of one plastic stent during the stenting period}

In this group, 18 patients were treated with a single pancreatic stent throughout the stenting period. The median number of procedures needed was three $(1-3)$. Stent migration was recorded in $3(17 \%)$ patients. Definitive stent removal was achieved in 12 patients (67\%), after a median stenting period of 14.5 months $(9-27)$. Re-stenting during FU was performed in seven patients (39\%). The median duration of FU was 81.5 months (50-116). Excluding one deceased patient, complete and partial treatment response were achieved in 15 patients (88.2\%) and one patient (5.9\%), respectively. Absence of treatment response was encountered in only one patient (5.9\%). The median IS at the end of the FU was $0(0-0)(\triangleright$ Table 2$)$. No complications occurred.

\section{Group B - Use of one or two plastic stents during the stenting period}

In group B, 35 patients were treated with one or two stents during the stenting period (31 starting with a single stent, passing to two stents and 4 starting with two and passing to a single stent). The median number of procedures needed was four $(3-5)$. Stent migration was seen in nine patients (26\%). Definitive stent removal was achieved in 30 patients (86\%), after a median stenting period of 23 months (16-33). Re-stenting during FU was necessary in 10 patients (29\%). The median duration of FU was 89 months (64-108). After excluding two deceased patients, complete and partial treatment response were achieved in 23 patients (74.2\%) and four patients 


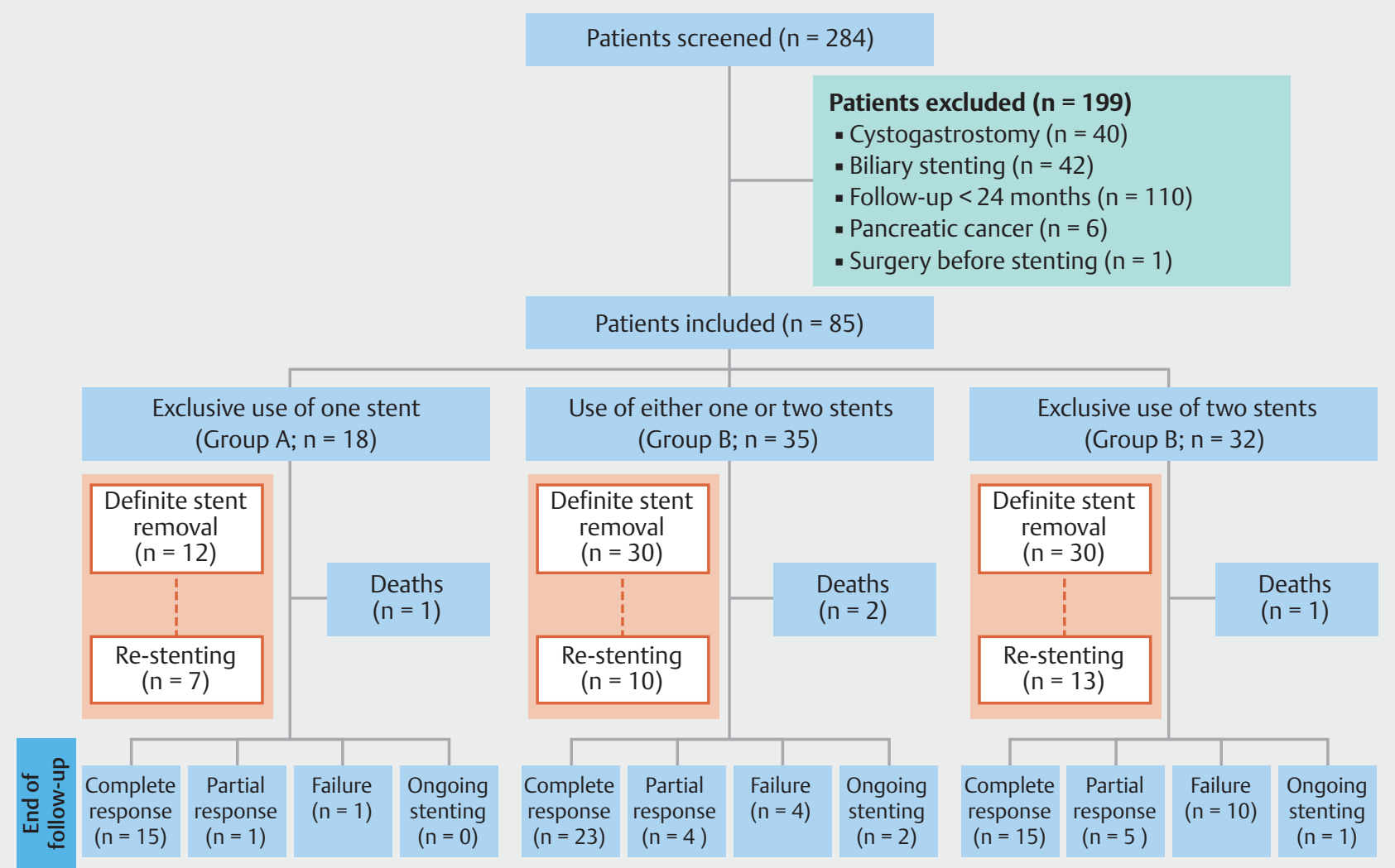

- Fig. 1 Study flowchart.

- Table 1 Demographic and clinical characteristics between groups at the beginning of endoscopic treatment.

\begin{tabular}{|c|c|c|c|c|}
\hline & $\begin{array}{l}\text { Group A } \\
n=18\end{array}$ & $\begin{array}{l}\text { Group B } \\
\mathbf{n}=35\end{array}$ & $\begin{array}{l}\text { Group C } \\
n=32\end{array}$ & $P$ \\
\hline Gender, male, n (\%) & $14(78)$ & $24(69)$ & $23(72)$ & 0.78 \\
\hline Median age, years (IQR) & $50(41-59)$ & $48(38-61)$ & $54(42-58)$ & 0.89 \\
\hline Chronic pancreatitis etiology, n (\%) & & & & 0.97 \\
\hline - Alcoholic & $12(67)$ & $24(69)$ & $21(66)$ & \\
\hline - Idiopathic & $6(33)$ & $11(31)$ & $11(34)$ & \\
\hline Median duration of chronic pancreatitis, months (IQR) & $22.5(9-69)$ & $13(8-84)$ & $51(10-74)$ & 0.28 \\
\hline Proximal pancreatic duct width (mm), median (IQR) & $7.4(5.3-8.9)$ & $6(4.7-8)$ & $6.9(5.3-9.4)$ & 0.27 \\
\hline Initial IS, median (IQR) & $46(34-55)$ & $31(19-53)$ & $44(20-63)$ & 0.35 \\
\hline Pancreas Divisum, n (\%) & $1(5.6)$ & $3(8.6)$ & $3(9.4)$ & 0.89 \\
\hline Intraductal stones necessitating ESWL, n (\%) & $14(78)$ & $16(46)$ & $24(75)$ & $0.02^{1}$ \\
\hline Current alcohol consumption, $\mathrm{n}(\%)$ & $12(67)$ & $15(43)$ & $16(50)$ & 0.26 \\
\hline Smoking, $\mathrm{n}(\%)$ & $14(78)$ & $22(63)$ & $25(78)$ & 0.31 \\
\hline Opioid usage, n (\%) & $3(17)$ & $12(34)$ & $7(22)$ & 0.31 \\
\hline Steatorrhea, n (\%) & $3(17)$ & $4(11)$ & $5(16)$ & 0.89 \\
\hline Diabetes mellitus, $\mathrm{n}(\%)$ & $3(17)$ & $4(11)$ & $8(25)$ & 0.56 \\
\hline
\end{tabular}


- Table 2 Comparison of treatment characteristics and clinical outcomes between groups.

\begin{tabular}{|c|c|c|c|c|}
\hline & $\begin{array}{l}\text { Group A } \\
(n=18)\end{array}$ & $\begin{array}{l}\text { Group B } \\
(n=35)\end{array}$ & $\begin{array}{l}\text { Group C } \\
(n=32)\end{array}$ & $P$ \\
\hline Median FU after stent insertion, months (IQR) & $81.5(50-116)$ & $89(64-108)$ & $79(47-107)$ & 0.37 \\
\hline Median duration of stenting, months (IQR) & $14.5(9-27)$ & $23(16-33)$ & $22.5(15-31)$ & 0.06 \\
\hline Number of ERCPs, median (IQR) & $3(1-3)$ & $4(3-5)$ & $3(2-3)$ & $0.001^{1}$ \\
\hline Patients alive at end of FU & 17 & 33 & 31 & 0.87 \\
\hline Ongoing stenting & $0(0 \%)$ & $2(6 \%)$ & $1(4 \%)$ & 0.29 \\
\hline Outcome of endoscopic treatment, n (\%) & & & & $0.02^{2}$ \\
\hline - Success & $15(88.2)$ & $23(74.2)$ & $15(50)$ & \\
\hline - Failure & $2(11.8)$ & $8(15.8)$ & $15(50)$ & \\
\hline - Partial response & 1 & 4 & 5 & \\
\hline - No response & 1 & 4 & 10 & \\
\hline IS at the end of FU, median (IQR) & $0(0-0)$ & $0(0-10)$ & $6(0-31)$ & $0.03^{3}$ \\
\hline Stent migration, n (\%) & $3(17 \%)$ & $9(26 \%)$ & $6(19 \%)$ & 0.87 \\
\hline Definitive stent removal, n (\%) & $12(67 \%)$ & $30(86 \%)$ & $30(94 \%)$ & 0.12 \\
\hline Re-stenting, n (\%) & $7(39 \%)$ & $10(29 \%)$ & $13(41 \%)$ & 0.66 \\
\hline Steatorrhea at the end of FU, n (\%) & $4(22 \%)$ & $7(20 \%)$ & $14(44 \%)$ & 0.89 \\
\hline Diabetes at the end of FU, $\mathrm{n}(\%)$ & $5(28 \%)$ & $7(20 \%)$ & $16(50 \%)$ & 0.56 \\
\hline $\begin{array}{l}\text { Group A: patients treated with exclusively one stent } \\
\text { patients treated with exclusively two stents during } \\
\text { ERCP, endoscopic retrograde cholangiopancreatogr } \\
{ }^{1} \text { After multiple correction, significant difference be } \\
{ }^{2} \text { After multiple correction, significant difference be } \\
{ }^{3} \text { After multiple correction, significant difference be }\end{array}$ & $\begin{array}{l}\text { lod; Group B: patien } \\
\text { range; IS, Izbicki sco } \\
\text { A and C }(P<0.05) \\
\text { C }(P=0.04) \\
\text { S A and B }(P<0.05)\end{array}$ & follow-up & ts during stenting & ; Group C \\
\hline
\end{tabular}

(12.9\%), respectively. Absence of treatment response was encountered in four patients $(12.9 \%)$, while two patients receive ongoing treatment with a stent in place $(\triangleright$ Table 2$)$.

Three complications of endoscopic treatment occurred in this group. Acute pancreatitis post-ERCP occurred in two patients, while one patient suffered a duodenal perforation due to difficult endoscope maneuvering. The duodenal perforation was treated by insertion of one double pigtail stent endoscopically through the perforation during the initial procedure; the two cases of acute pancreatitis were treated conservatively. Patient outcome after respective treatment was excellent.

\section{Group C-Exclusive use of two plastic stents during the stenting period}

In this group, all 32 patients had two stents inserted during the stenting period. The median number of procedures needed for this group was three $(2-3)$. Stent migration was seen in $19 \%$ ( $n$ $=6$ ) of the patients. Distal migration occurred in five patients and proximal migration occurred in one patient. Definitive stent removal was achieved in 30 patients (94\%) after a median total duration of stenting of 22.5 months (15-31). Re-stenting was required in 13 patients (41\%). The median duration of FU was 79 months $(47-107)$. The median IS at the end of the FU was six $(0-31)$. After excluding the patient who died during
FU, complete and partial treatment response were achieved in 15 patients (50\%) and five patients (16.7\%), respectively ( $\triangleright$ Fig.2). Absence of treatment response was encountered in 10 patients (33.3\%). One patient had stents still in place at the end of FU ( $\triangleright$ Table 2 ). No complications related to the endoscopic procedures were recorded in this group.

\section{Comparison of outcomes}

- Table 2 illustrates the treatment characteristics and outcomes between the three different groups. Statistically significant difference within the groups was seen in the median number of endoscopic procedures needed, which was higher for group B (patients with one or two stents) [3 (A) vs. 3 (C) vs. 4 (B), $P=0.001]$. Moreover, the stenting duration tended to be shorter in Group A patients (patients treated with exclusively one stent) [14.5 (A) vs. 23 (B) vs. 22.5 (C) months, $P=0.06]$. Regarding the primary objective ( $\downarrow$ Table 2 ), clinical success of endoscopic treatment was lower (50\%) in Group C (exclusively two stents during the stenting period) compared to patients of groups $A$ and $B(88.2 \%$ and $74.2 \%$, respectively; $P=0.02)$. After multiple comparisons, the only significant difference regarding clinical success was identified between patients of Group A compared to those of Group C [OR(95\%Cl): $7.50(1.46-$ 38.70); $P=0.04]$. Clinical success did not differ between Group 

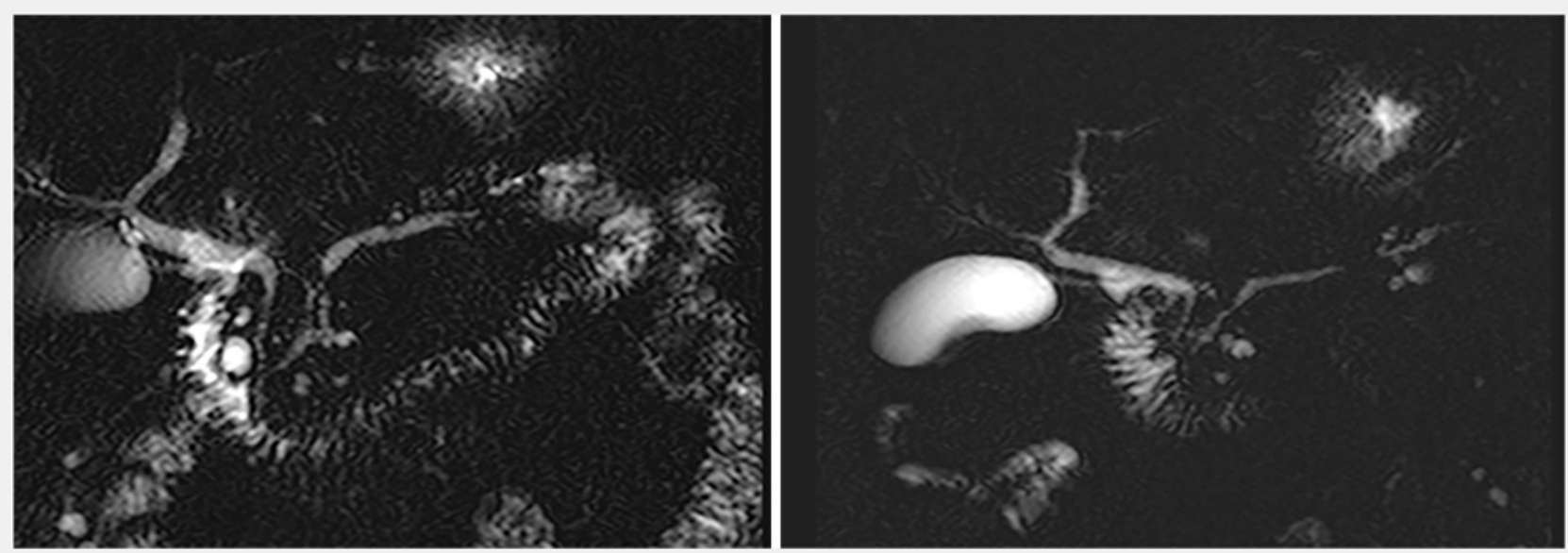

Fig. 2 Magnetic resonance cholangiopancreatography of a patient with main pancreatic duct stricture at the level of the head of the pancreas. The left image demonstrates the stricture before endoscopic treatment and the right image its resolution after a 2-year treatment with two plastic stents.

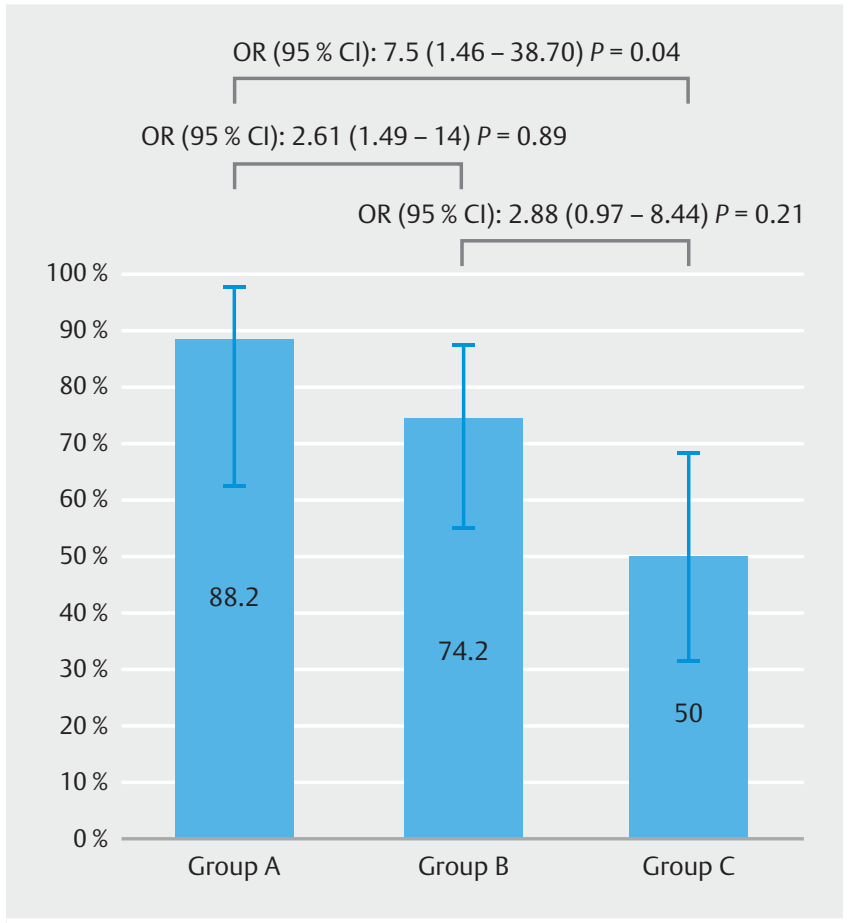

Fig. 3 Proportions of successful endoscopic treatment outcomes per group and intergroup difference in outcome. (The error bars represent the $95 \% \mathrm{Cl}$ of the proportions; the p-values represent the values of the Fisher exact test and the OR $[95 \% \mathrm{Cl}]$ represent the ratio of success/failure within the first group divided by the ratio of success/failure within the second group).

B and either Group A or Group C ( $\triangleright$ Fig.3). Similarly, the only proportional difference in the outcome between the three groups that remained statistically significant was the difference between Group A and Group C [Difference: 38.2\% (6.4\% - 59\%); - Supplemental Table].
- Table 3 illustrates the univariate and multivariable analysis performed to identify factors significantly associated with successful endoscopic treatment. After adjustment for age and alcohol, the only factor that was statistically associated with successful endoscopic treatment outcome was the treatment group $(P=0.04)$. We observed a higher odds ratio of group $A$ compared to group $C[\mathrm{aOR}(95 \% \mathrm{Cl})$ : $6.49(1.20-35.10) ; P=$ 0.03 ] and a slight decrease compared to the crude OR. As expected, IS at the end of FU was statistically higher in group $C$ compared to groups A and B (6 vs. 0 vs. 0 , respectively; $P=$ $0.03)$. Finally, a higher number of procedures was necessitated for patients undergoing the step-up stenting approach (Group B). We did not detect any other statistically significant differences between the three groups.

\section{Discussion}

Pancreatic duct stenting is the mainstay of endoscopic treatment for MPD dominant strictures. Over the years a number of publications have shown good long-term response rates ranging from $52 \%$ to $83 \%$ [8-13] ( Table 4). Despite these outcomes a subset of patients will not respond to endoscopic treatment and may still need surgical intervention. Insertion of multiple pancreatic stents has been proposed as an effective treatment modality aiming to achieve better response rates [4]. In this cohort, multiple pancreatic duct stenting resulted in a long-term response rate of $84 \%$ [4]. More recent results from the same group showed long-term response rates of $75 \%$ over a mean FU period of 9.5 years in patients treated with multiple stents. The remaining $25 \%$ of patients had pain recurrence over a mean period of 2.2 years treated by duct clearance or restenting [14]. In both studies no control group was available [4, 14].

To our knowledge our study is the first one comparing success of endoscopic treatment in patients with CP and distal MPD stricture treated with either exclusively one or exclusively 
- Table 3 Univariate and multivariable analysis of factors associated with successful endoscopic treatment.

\begin{tabular}{|c|c|c|c|c|}
\hline & \multicolumn{2}{|l|}{ Univariate analysis } & \multicolumn{2}{|c|}{ Multivariable analysis (success $/$ failure cases $=53 / 25$ ) } \\
\hline & OR (95\%Cl) & $P$ value & aOR $(95 \% \mathrm{Cl})$ & $P$ value \\
\hline \multicolumn{5}{|l|}{ Treatment group } \\
\hline Group C (reference) & 1 & \multirow[t]{3}{*}{0.02} & 1 & \multirow[t]{3}{*}{0.04} \\
\hline Group B & $2.88(0.97-8.44)$ & & $2.91(0.95-8.98)$ & \\
\hline Group A & $7.50(1.46-38.70)$ & & $6.49(1.20-35.10)$ & \\
\hline Age & $1.04(1.01-1.08)$ & 0.04 & $1.04(0.99-1.08)$ & 0.11 \\
\hline Gender & $0.98(0.34-2.84)$ & 0.98 & & \\
\hline Pancreatitis etiology & $1.30(0.47-3.56)$ & 0.61 & & \\
\hline Alcohol & $2.71(1.01-7.25)$ & 0.05 & $2.16(0.75-6.24)$ & 0.16 \\
\hline Smoking & $0.69(0.22-2.21)$ & 0.54 & & \\
\hline Opioids use & $1.20(0.22-6.65)$ & 0.84 & & \\
\hline Intraductal stones necessitating ESWL & $2.08(0.71-6.06)$ & 0.18 & & \\
\hline Diabetes & $1.50(0.37-6.10)$ & 0.57 & & \\
\hline Steatorrhea & $1.12(0.26-4.73)$ & 0.88 & & \\
\hline Pancreas Divisum & $2.50(0.28-22.61)$ & 0.42 & & \\
\hline Disease duration & $1.00(0.99-1.01)$ & 0.97 & & \\
\hline Stenting duration & $1.01(0.98-1.05)$ & 0.48 & & \\
\hline Proximal pancreatic duct width & $0.91(0.76-1.08)$ & 0.27 & & \\
\hline
\end{tabular}

- Table 4 Selected long-term studies on single plastic stenting for pancreatic duct strictures in chronic pancreatitis.

\begin{tabular}{|l|l|l|l|l|l|}
\hline Author (ref) & $\begin{array}{l}\text { Number of } \\
\text { patients }\end{array}$ & $\begin{array}{l}\text { Follow-up } \\
\text { (months) }\end{array}$ & $\begin{array}{l}\text { Stenting duration } \\
\text { (months) }\end{array}$ & $\begin{array}{l}\text { Long-term clinical } \\
\text { success (\%) }\end{array}$ & $\begin{array}{l}\text { Need for } \\
\text { re-stenting (\%) }\end{array}$ \\
\hline Binmoeller et al (8) & 93 & 58 & 15.7 & 65 & 27 \\
\hline Eleftheriadis et al (9) & 100 & 69 & 23 & 62 & 38 \\
\hline Weber et al (10) & 17 & 24 & 5.6 & 63 & 30 \\
\hline Vitale et al (11) & 89 & 43 & 12 & 52 & N/A \\
\hline Cremer et al (12) & 75 & 37 & N/A & 63 & N/A \\
\hline Rösch et al (13) & 478 & 52 & & & N/A \\
\hline N/A, non-available; Ref, reference & & & & \\
\hline
\end{tabular}

two or a combination of one or two stents during the stenting period. Overall, our results regarding treatment response rates in both groups were in line with current literature findings. Our study did not detect any significant difference for use of two pancreatic stents from the beginning of endotherapy in terms of clinical success. On the contrary, our results with higher rates of successful endoscopic treatment in groups $A$ and $B$ may favor a more conservative, step-by-step approach starting with single stent deployment and proceeding to double stenting if MPD stricture calibration seems to be insufficient after one period of treatment with a single stent.
Pancreatic stenting can induce ductal changes such as ductal stenosis, dilatation of side branches, ductal irregularity, and even parenchymal changes [15]. These changes are thought to be reversible after stent removal but infrequently can lead to severe and irreversible parenchymal pathology [16]. One can speculate that immediate double pancreatic stenting, as performed in patients from group C, may be more traumatic, resulting in more severe ductal changes with longer resolution time and worsening of the symptoms in comparison with single stenting. Also changing to multiple stenting after a period of single stenting in case of response failure may be a safer ap- 
proach overcoming this problem by providing enough time to the pancreatic duct to adjust in the changes caused by the stent.

On the other hand, our study showed that patients of group $B$ (most of them following the step-up approach) underwent a significantly higher number of endoscopic procedures compared to Group C (patients with exclusively two stents). In the latter group, inserting more than one stents from the beginning of the stenting period may reduce morbidity related to the exchange procedure, probably due to longer patency periods. Stent occlusion is a well-known complication of stent placement [17], which may occur less frequently during multiple pancreatic stenting due to maintenance of pancreatic juice flow alongside the stents even if there is stent clogging [4].

Fully-covered self-expandable metal stents (SEMS) also have been proposed as an alternative treatment option to plastic stents for MPD strictures [18]. Their larger diameter is the main advantage compared to plastic stents providing possibly better calibration of MPD strictures. Reported success rates range from $38 \%$ to $90 \%$ [19-21]. In a recent small series study, a high percentage of migration was reported (47\%), while de novo stricture formation due to SEMS deployment was seen in $27 \%$ of the patients highlighting possible limitations in SEMS usage for this subset of patients [22].

Limitations of the current study are linked to its retrospective nature. The three groups, although comparable, were not similar regarding the morphological characteristics of their disease. Patients in Group B underwent less ESWL at the beginning of endoscopic treatment [46\% (B) vs. $78 \%(A)$ vs. $75 \%(C)$ ]; this might translate to the fact that in these patients, the ductal obstruction was more related to strictures than stones, and therefore, could influence clinical outcome. Furthermore, there were no clear criteria on the number of stents deployed in each patient, or for minimum stenting duration. Although not statistically significant, stent duration was shorter for Group A, also reflecting a lower definitive stent removal rate $[67 \%(A)$ vs. $86 \%$ (B) vs. $94 \%$ (C)]. Moreover, all patients received up to two $8.5 \mathrm{Fr}$ or $10 \mathrm{Fr}$ stents, possibly rendering stricture calibration suboptimal in the multiple stenting patient group, compared with previous studies, where two or more $10 \mathrm{Fr}$ stents were placed [4] and peri-procedural technical difficulties were not taken under consideration in this study. Proximal migration of the first stent during the second stent insertion is known to occur and can prolong procedure time.

The optimal strategy for handle MPD strictures in patients with CP pends out and current recommendations are based on low quality of evidence [3]. High-quality RCTs comparing different endoscopic treatment approaches (e. g. single versus multiple stenting) would be of great value to elucidate ideal treatment. Taking into consideration current ESGE recommendations [3] and our study's results, starting endoscopic treatment of $\mathrm{CP}$ strictures using a single plastic stent seems reasonable. The number of stents can be increased during the first stenting period, a feature that may increase definitive stent removal rate. Furthermore, an on-demand stent exchange policy may reduce the number of interventions. After a period of approximately 12 to 24 months, definitive stent removal should be considered, knowing that one-third of patients will have a pain relapse during which discussion between re-stenting and surgery should take place.

\section{Conclusion}

In conclusion, our study supports that pancreatic stenting could be an appropriate treatment for management of MPD strictures in $\mathrm{CP}$, but further RCTs to prove its efficacy are warranted. In our study, initial single stenting deployment was associated with a higher rate of clinical success compared to patients with initial placement of two stents. Similarly, single stenting was the only factor identified as factor predictive of successful endoscopic treatment. On the contrary, use of multiple stents initially was related to a decreased number of endoscopic procedures needed in comparison with a step-up approach. As already mentioned, further well-designed RCTs are warranted to elucidate the optimal management of this subset of patients.

\section{Acknowledgements}

Drs. Papalavrentios and Gkolfakis acknowledge the Hellenic Society of Gastroenterology for providing them an educational support grant in therapeutic endoscopy.

Competing interests

None

References

[1] Mitchell RM, Byrne MF, Baillie J. Pancreatitis. Lancet 2003; 361: 1447 1455

[2] Delhaye M, Matos C, Deviere J. Endoscopic technique for the management of pancreatitis and its complications. Best Practice \& Research Clinical Gastroenterology 2004; 18: 165-173

[3] Dumonceau JM, Delhaye M, Tringali A et al. Endoscopic treatment of chronic pancreatitis: European Society of Gastrointestinal Endoscopy (ESGE) Clinical Guideline-Updated August 2018. Endoscopy 2019; 51: $179-193$

[4] Costamagna G, Bulajic M, Tringali A et al. Multiple stenting of refractory pancreatic duct strictures in severe chronic pancreatitis: longterm results. Endoscopy 2006; 38: 254-259

[5] Löhr JM, Dominguez-Munoz E, Rosendahl J et al. United European Gastroenterology evidence-based guidelines for the diagnosis and therapy of chronic pancreatitis (HaPanEU). United European Gastroenterol J 2018; 18: $146-160$

[6] Bloechle C, Izbicki JR, Knoefel WT et al. Quality of life in chronic pancreatitis-results after duodenum-preserving resection of the head of the pancreas. Pancreas 1995; 11: 77-85

[7] Delhaye M, Matos C, Devière J. Endoscopic management of chronic pancreatitis. Gastrointest Endosc Clin N Am 2003; 13: 717- 742

[8] Binmoeller KF, Jue P, Seifert $\mathrm{H}$ et al. Endoscopic pancreatic stent drainage in chronic pancreatitis and a dominant stricture: long-term results. Endoscopy 1995; 27: 638-644 
[9] Eleftheriadis N, Dinu F, Delhaye M et al. Long-term outcome after pancreatic stenting in severe chronic pancreatitis. Endoscopy 2005; 37: $223-230$

[10] Weber A, Schneider ], Neu B et al. Endoscopic stent therapy for patients with chronic pancreatitis: results from a prospective follow-up study. Pancreas 2007; 34: 287 - 294

[11] Vitale GC, Cothron K, Vitale EA et al. Role of pancreatic duct stentingin the treatment of chronic pancreatitis. Surg Endosc 2004; 18 : $1431-1434$

[12] Cremer M, Devière J, Delhaye M et al. Stenting in severe chronic pancreatitis: results of medium-term follow-up in seventy-six patients. Endoscopy 1991; 23: 171 - 176

[13] Rösch T, Daniel S, Scholz M et al. Endoscopic treatment of chronic pancreatitis: a multicenter study of 1000 patients with long-term follow-up. Endoscopy 2002; 34: 765 - 771

[14] Bove V, Tringali A, Valerii G et al. Endoscopic dilation of pancreatic duct strictures in chronic pancreatitis with multiple plastic stents: results in 48 patients. Gastrointest Endosc 2017; 85: AB236 (Suppl.)

[15] Sherman S, Hawes R, Savides T et al. Stent induced pancreatic ductal and parenchymal changes: correlation of endoscopic ultrasound with ERCP. Gastrointest Endosc 1996; 44: $276-282$
[16] Alvarez C, Robert M, Sherman S et al. Histologic changes after stenting of the pancreatic duct. Arch Surg 1994; 129: 765-768

[17] Devière J. Why do pancreatic stents become occluded? Gastrointest Endosc 2005; 61: $867-868$

[18] Shen Y, Liu M, Chen M et al. Covered metal stent or multiple plastic stents for refractory pancreatic ductal strictures in chronic pancreatitis: a systematic review. Pancreatology 2014; 14: 87-90

[19] Giacino C, Grandval P, Laugier R. Fully covered self-expanding metal stents for refractory pancreatic duct strictures in chronic pancreatitis. Endoscopy 2012; 44: 874-877

[20] Matsubara S, Sasahira N, Isayama H et al. Prospective pilot study of fully covered self-expandable metal stents for refractory benign pancreatic duct strictures: long-term outcomes. Endoscopy International Open 2016; 4: E1215-E1222

[21] Oh D, Lee JH, Song T] et al. Long-term outcomes of 6-mm diameter fully covered self-expandable metal stents in benign refractory pancreatic ductal stricture. Digestive Endoscopy 2018; 30: 508 - 515

[22] Tringali A, Vadalà di Prampero SF et al. Fully covered self-expandable metal stents to dilate persistent pancreatic strictures in chronic pancreatitis: long-term follow-up from a prospective study. Gastrointest Endosc 2018; 88: $939-946$ 
- Supplemental Table Difference in proportion of successful treatment between the three groups

\begin{tabular}{|l|l|}
\hline Groups & Difference $\mathbf{( 9 5} \% \mathrm{CI})$ \\
\hline Group A vs. Group B & $14 \%(-15.1 \%-35.5 \%)$ \\
\hline Group A vs. Group C & $38.2 \%(6.4 \%-59 \%)$ \\
\hline Group B vs. Group C & $24.2 \%(-2.3-46.8 \%)$ \\
\hline
\end{tabular}

